\title{
BEDLOAD TRANSPORT MEASUREMENTS ON THE MAROS RIVER, HUNGARY
}

\section{TÍMEA KISS ${ }^{1 *}$, GABRIEL J. AMISSAH ${ }^{1}$, GÁBOR MEZŐSI ${ }^{1}$, KÁROLY FIALA², GYÖRGY SIPOS ${ }^{1}$}

${ }^{1}$ Department of Physical Geography and Geoinformatics, University of Szeged, Szeged

${ }^{2}$ Lower Tisza Water Directorate, Szeged

*Email: kisstimi@gmail.com

Received 18 March 2021, accepted in revised form 23 April 2021

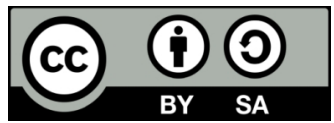

\begin{abstract}
Sediment transport is a vital component in hydrological and fluvial geomorphological studies, however, the temporal and spatial changes in sediment fluxes, and the efficiency of bedload samplers are rarely analysed, as bedload measurements are quite difficult. The aim of the present study is to measure the bedload transport of the sand-bedded Maros River (Hungary) at low stages using the Helley-Smith bedload sampler. In order to understand the variability in the bedload transport, the water stage and discharge across the channel section were also measured. The variability of the bedload was caused by an active in-channel bar and translational sediment pulses. The created bedload transport rating curve could be applied just below $300 \mathrm{~m}^{3} / \mathrm{s}$ water discharge thus further measurements are needed to evaluate the bedload transport of higher discharges.
\end{abstract}

Keywords: bedload sampler, sediment transport, bar migration, bedload transport rating curve

\section{Introduction}

Sediment transport in alluvial rivers plays a significant role in altering river morphology, influencing the navigation routes, the stability of engineering constructions such as bridge piers and reservoirs, and the success of river management works. However, no single apparatus or procedure have been universally accepted as completely satisfactory for the determination of bedload discharge over wide range of sediment and hydraulic conditions due to lack of adequate information to support performance (Gomez 1991).

The Maros River (Hungary) transports large quantity of sandy bedload and has highly changeable river bed. To understand the fluvial processes of the river data on bedload transport are needed, therefore we aimed (1) to do bedload measurements by the Helley-Smith bedload sampler, and (2) to characterise the spatial and temporal variations in sediment discharge at a transect of the river; and 3) to create a bedload transport rating curve for the river.

\section{Study Area}

The Maros River (length: 750 km; catchment area: ca. $30000 \mathrm{~km}^{2}$ ) is one of the largest and most dynamically changing rivers in the Carpathian Basin (Fig. 1; Kiss and Sipos, 2007). The Maros and its tributaries are fed 
mainly by precipitation and overland flow. The mean discharge at the Makó gauging station is $161 \mathrm{~m}^{3} / \mathrm{s}$, while the maximum discharge on record was measured in 1974 and it was $2450 \mathrm{~m}^{3} / \mathrm{s}$ (Sipos et al. 2007). According to a former survey (Bogárdi 1974) the river transports significant amount of sediment, as its mean suspended sediment concentration is $500 \mathrm{~g} / \mathrm{m}^{3}$; its annual suspended sediment transport is $8.3 \mathrm{million} \mathrm{t} / \mathrm{y}$ and its bedload transport is $28000 \mathrm{t} / \mathrm{y}$. The bedload of the river comprises of medium and coarse sand which is extracted from the channel in both Hungary and Romania (Sipos et al., 2007; Kiss et al., 2017).

The Maros has been the subject of intense human activities due to its economic importance (Sipos et al., 2012). As a consequence of the of 19th century river regulation works (i.e. construction of levees, artificial meander cut-offs), the originally meandering/anastomosing pattern of the river was artificially changed to strait or slightly sinuous, however during the last century it was naturally developed towards an island-braided pattern (Sipos, 2006).

The study was carried out at the transect of the Hungarian section of the Maros River at the Makó gauge station $24.5 \mathrm{~km}$ upstream of its confluence with the Tisza River (Fig. 1). The river at this location is straightened and stabilized by stone revetments on both banks. Its mean width is $140 \mathrm{~m}$, while its mean bankfull depth is $3.6 \mathrm{~m}$, thus its mean

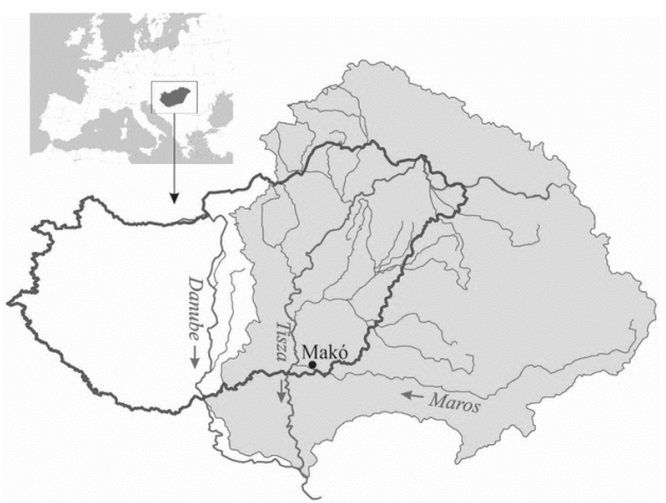

cross-sectional area is ca. $500 \mathrm{~m}^{2}$. At the Makó gauge station, the bedload consists of medium and coarse sand.

The sediment sampling site can be considered as representative, based on the criteria of van Rijn (1986), as the studied cross-section is located in a stable reach of the river, it is sufficiently deep for sampling, and it has normal flow direction.

\section{Methods}

The measurements were made along the wired monitoring section, equipped with an electric engine moving the measuring devices along the same cross-section, which enabled us to do the measurements exactly at the same distance from the right bank. Bedload sediments were collected at eight locations at $10 \mathrm{~m}$ intervals (Fig. 1) using a Helley-Smith bedload sampler. Its entrance nozzle is $7.6 \mathrm{~cm}$ $\times 7.6 \mathrm{~cm}$ sized, and the sediment is collected in a sample bag (250 $\mu \mathrm{m}$-mesh), thus it can trap medium sand or coarser sediments. Sampling was done applying 60 s sampling durations, as in a previous study (Amissah 2020) it was found to be the most effective. Simultaneously, an acoustic Doppler current profiler (ADCP) was also used across the transect to measure the mean velocity and water depth, while the water stage was read at the fluviometer at Makó on each sampling day.

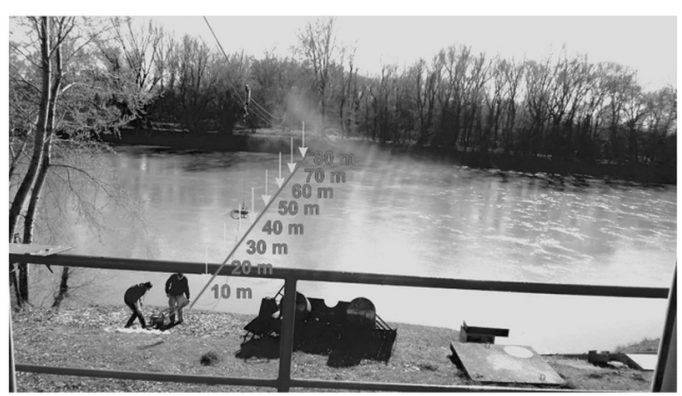

Fig. 1. The measurements were made on the lowland section of River Maros, at the Makó gauge station. The sampling points are located at $10 \mathrm{~m}$ intervals. 


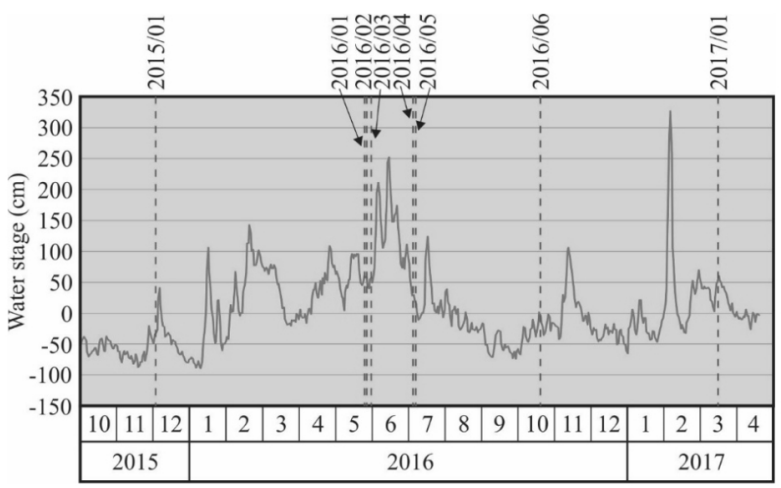

Fig. 2. Water stage of the Maros at Makó between October 2015 and April 2017 showing the bedload sampling days

During the studied period, only stages below bankfull level $(350 \mathrm{~cm})$ occurred (Fig. 2). Bedload measurements were performed once in 2015, six times in 2016 and once in 2017. Throughout the sampling campaigns the water stages were close to the annual mean. The collected samples were dried and weighed, and these data were evaluated.

\section{Results and discussion}

\section{Channel morphology and spatial variation of bedload yield}

In sand-bedded rivers like the Maros, the cross-sectional profile of the channel can change quite rapidly even within the same day (Fig. 3). For example, during sampling day 2016/06 in less than an hour the bed elevation had changed by $\mathrm{ca} .10 \mathrm{~cm}$ on the mid-channel bar (at 40-60 $\mathrm{m}$ from the bank) and by $30 \mathrm{~cm}$ on the lateral bar (at 70-80 $\mathrm{m}$ from the bank), referring to ripple-mark and sandbar migration.
According to our results the daily and long-term channel bed variations influence the spatial variation of collected bedload masses. To present the spatial changes the results of 2016/04 sampling campaign were used, when in each hour the sampling was repeated at each sampling point during the day, thus 7 samples were collected at each point (Fig. 4). Although the $20 \mathrm{~m}$ sampling point was expected to have a high sediment yield based on previous sampling campaigns, the bedload transport had a relatively low yield (max: $1.2 \mathrm{~kg}$ ) with a corresponding low standard error. The highest bedload yield was recovered at the $70 \mathrm{~m}$ location (max: 2.4 $\mathrm{kg}$ ) on the edge of the lateral bar.

To better understand the connection between morphological changes and bedload transport, the grain-size distribution of collected sediment was also analysed. The least sorted sediments were collected at the edges of the bar by the thalweg (at 10$30 \mathrm{~m}$; Fig. 5A), whilst the most well-sorted sediments were found on the highest area of the lateral bar (at 60-80 m). The high

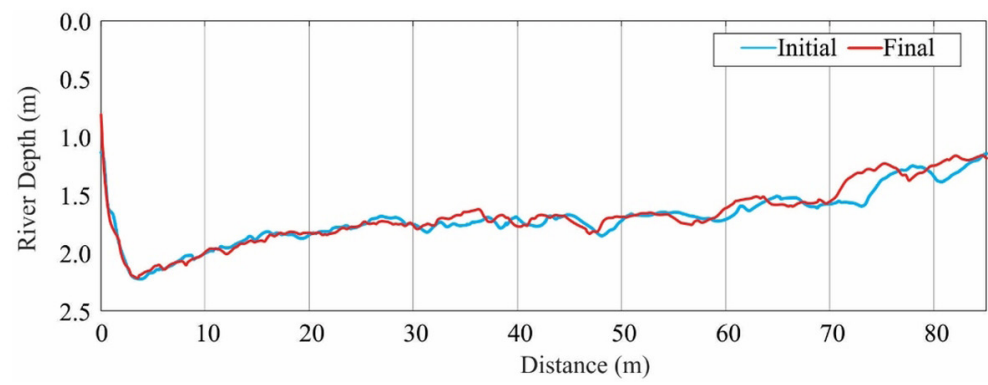

Fig. 3. Cross-sectional channel-bed changes of the Maros during an hour on the 2016/06 field campaign 


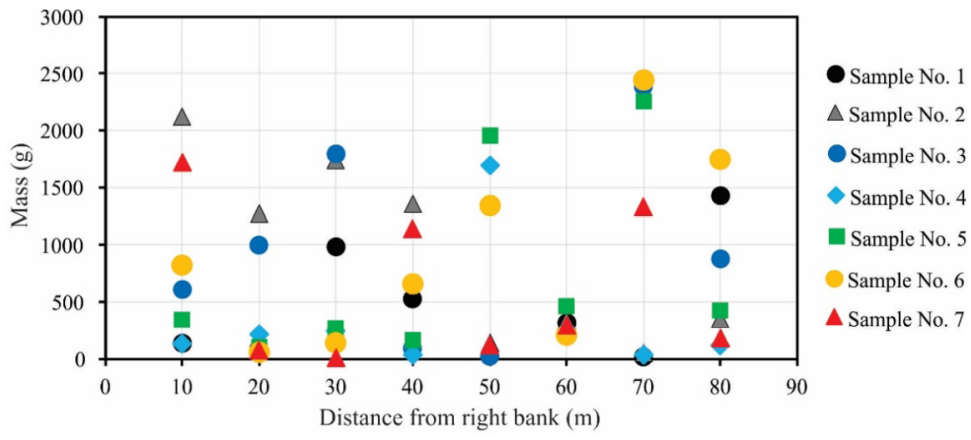

Fig. 4. Repeated measurements on the same day at the same points revealed great variability in bedload transport even during short time.
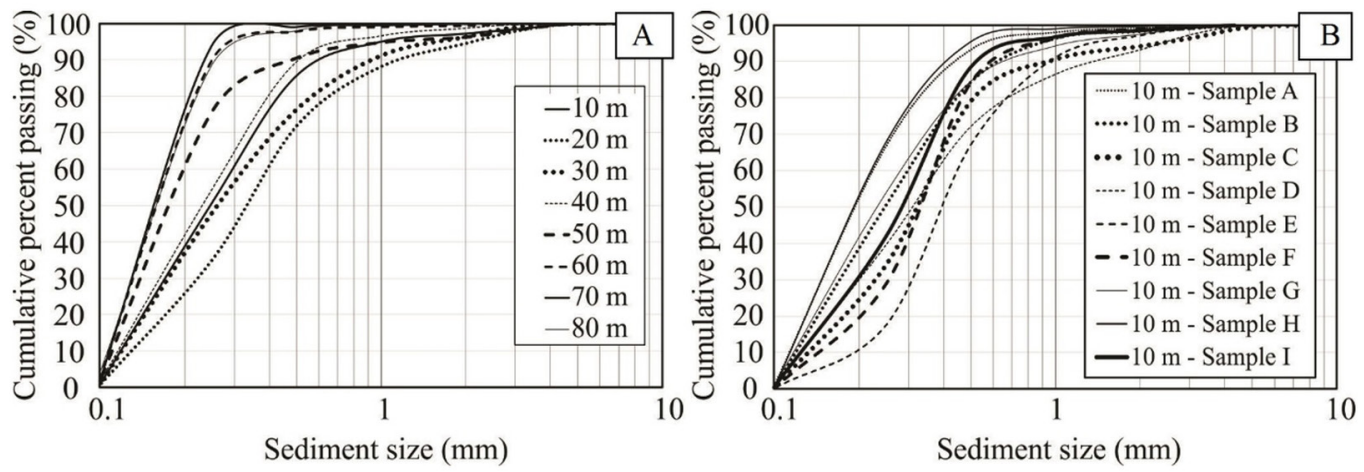

Fig. 5. Grain-size distribution of the collected sediment at various distances from the right bank (A), and its variability at the same point between the different sampling campaigns (B)
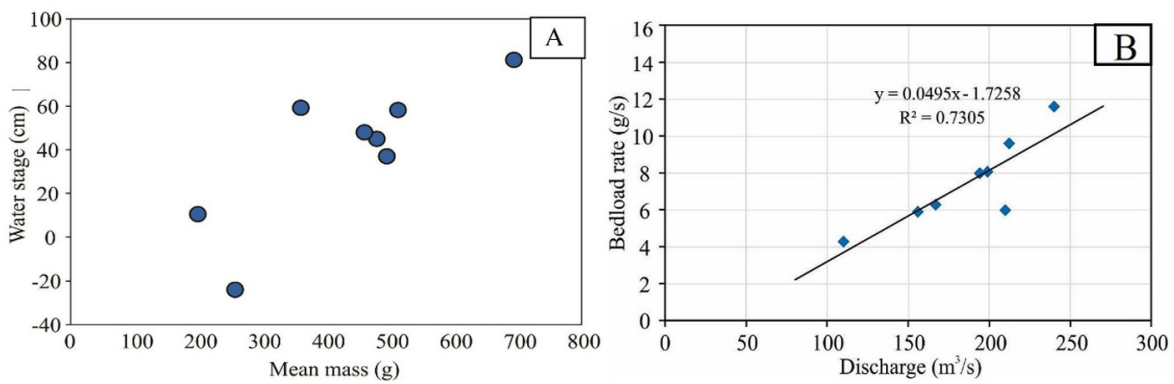

Fig. 6. Relationship between water stage and measured bedload (A), and the created bedload transport rating curve (B) at the Makó gauge station

variability of grain-size distribution of the bead-load is also reflected by the samples collected from the thalweg (at $10 \mathrm{~m}$ ), where the grain-size varied considerably between the sampling campaigns (Fig. 5B).

The mean bed-load masses were compared to the water stages. The result shows strong correlation between the stage and mean bedload mass (Fig. 6A). Based on these results the sediment rating curve for the Maros at Makó was created (Fig. $6 \mathrm{~B}$ ), however it is valid just for medium to low stages, or discharges lower than 300 $\mathrm{m}^{3} / \mathrm{s}$. The results showed strong correlation between the time-normalized masses and the discharge $\left(\mathrm{R}^{2}=0.7305\right)$. To extend the curve to higher stages and discharge conditions, further measurements during higher stages 
are needed.

\section{Conclusions}

High temporal and spatial variability in bedload transport was measured, as the channel morphology (e.g. location of the thalweg) and the changing bed-forms of the Maros fundamentally influence the bedload transport. These results are in accordance with the results of Gran and Czuba (2017), who explained this variability by translational sediment pulses. In case of the Maros, the shifting mid-channel bars across the channel are also responsible for this variability. The frequent movement of bed-forms could be explained by the high slope of the river, as it was proven by Ghilardi et al. (2014). However, bedload changeability could also be the result of the various positions of the HelleySmith sampler (Vericat et al. 2006), and its insufficient trapping capacity (Emmett 1980, 1981).

As the created bedload - water discharge rating curve is just valid for water discharges less than $300 \mathrm{~m}^{3} / \mathrm{s}$, more data covering higher stages are needed to estimate the bedload transport, as much higher discharge were also measured on the Maros, so the interval between $300 \mathrm{~m}^{3} / \mathrm{s}$ and $2620 \mathrm{~m}^{3} / \mathrm{s}$ should be also covered.

\section{Acknowledgement}

The research was supported by Hungarian Research Foundation (OTKA 119193) and the Stipendium Hungaricum Programme.

\section{References}

Amissah, G.J., (2020): Channel processes of a large alluvial river under human impacts. PhD Dissertation, University of Szeged, Szeged.

Bogárdi, J., (1974): Sediment transport in alluvial streams. Akadémiai Kiadó.

Emmett, W. W. (1981): Measurement of bedload in rivers. Erosion and Sediment Transport
Measurement. Proceedings of the Florence Symposium. IAHS Publ. No. 133.

Emmett, W. W. (1980): A field calibration of the sediment-trapping characteristics of the Helley-Smith bed-load sampler. USGS Numbered Series No. 1139, Professional Paper.

Ghilardi, T. - Franca, M. J. - Schleiss, A. J. (2014): Bed load fluctuations in a steep channel. Water Resources Research, 50(8), 6557-6576.

Gran, K. B. - Czuba, J. A. (2017): Sediment pulse evolution and the role of network structure. Geomorphology, 277, 17-30.

Kiss, T. - Sipos, G. (2007): Braid-scale channel geometry changes in a sand-bedded river: Significance of low stages. Geomorphology, 84(3), 209-221.

Kiss, T. - Nagy, Z. - Balogh, M. (2017): Floodplain level development induced by human activity - Case study in the lower Maros/Mures river, Romania and Hungary. Carpathian Journal of Earth and Environmental Sciences, 12(1), 83-93.

Sipos, G. (2006): A meder dinamikájának vizsgálata a Maros magyarországi szakaszán (Channel dynamics on the Hungarian section of the Maros River). PhD Dissertation, University of Szeged, Szeged.

Sipos, G. - Kiss, T. - Fiala, K. (2007): Morphological alterations due to channelization along the lower Tisza and Maros rivers (Hungary). Geogr. Fis. Dinam. Quat., 30, 239-247.

Sipos, G. - Právetz, T. - Katona, O. - Ardelean, F. Timofte, F. - Onaca, A. - Kiss, T. - Kovács, F. - Tobak, Z. (2012): The ever-changing river. In Sipos Gy. (Ed.): Past, present, future of the Maros/Mureș River. Department of Physical Geography and Geoinformatics, University of Szeged, pp. 179-192.

van Rijn, L. C. (1986): Manual sediment transport measurements. Delft Hydraulics Laboratory, Delft, The Netherlands.

Vericat, D. - Church, M. - Batalla, R. J. (2006): Bed load bias: Comparison of measurements obtained using two (76 and $152 \mathrm{~mm}$ ) Helley-Smith samplers in a gravel bed river. Water Resources Research, 42(1), W01402. 